\title{
A Supplementary Note on Ice Crystal Growth
}

\author{
By \\ Toshiichi ôkita \\ Geophysical Institute, Asahikawa Branch, Hokkaido Gakugei University
}

(Manuscript received 29 July 1954)

In the article "Ice Crystal Growth in the Atmosphere" which was published in Vol. 32, No. 5 of this journal, the authors compared the observed growth rates of plates with the values predicted by Houghton's theory(1) (Fig. I1 of the article) and did not give attention to the growth of ice sphere. However, it seems more reasonable to compare the observed growth rates of the plates with the calculated values for " ice sphere" rather than those for "plates," because the thickness of many plates equals the

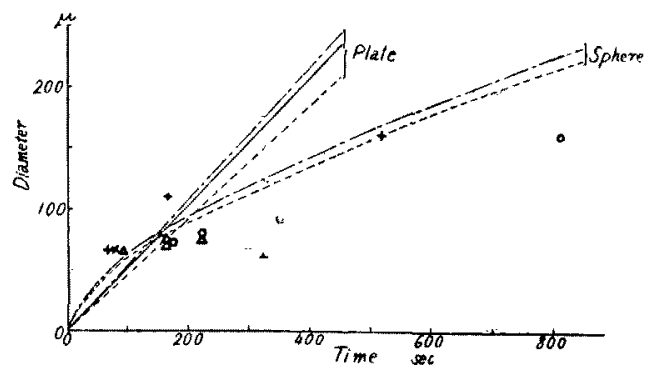

Fig. 1. Size of ice erystals as a function of elapsed time

Calculated values $-\cdots$ at $-16^{\circ} \mathrm{C}$

$\longrightarrow$ at $-12^{\circ} \mathrm{C}$

.... at $-20^{\circ} \mathrm{C}$

Measured values $\times$ Feb. 3

$\bigcirc$ Feb. 27

$\triangle$ Mar. 6

diameter of their basal plane as shown in Fig. 7 of the article.
Fig. 1 is reproduced from Fig. 11 of the article. In the figure the diameter of ice sphere calculated by using Houghton's method is plotted against elapsed time. Calculation is made at the air temperature of $-16^{\circ} \mathrm{C}$ and $-20^{\circ} \mathrm{C}$ and at water saturation on the assumption that the density of the sphere is 0.9 and we use the value of the velocity coefficient $K_{v}$ given by Houghton and Radford(2) experimentally. Generally, there is a considerably better agreement between observed and calculated values in the case of "ice sphere" than in the case of "plates". However, even in the case of ice sphere, for the elapsed time larger than about $150 \mathrm{sec}$ observed size is generally less than the calculated one. It is partly due to the fact that larger crystals had fallen upon the ground before they reached more distant points.

\section{References}

(1) H. G. Houghton : A Preliminary Quantitative Analysis of Precipitation Mechanisms. Journ. Met., 7, 363 (1950).

(2) H. G. Houghton and W. H. Radford : On the Local Dissipation of Natural Fog. Pap. Phys. Ocean. Met., M. I. T,. 6 No. 3, 63 (1938). 